EUROPEAN HONORS COUNCIL

Note

\title{
Designing an Honors Peer Advising Center
}

Amber Zoe Smith ${ }^{1}$

1.VVirginia Tech Honors College, United States of America; azsmith@vt.edu

Received: 8 August 2017; Accepted: 28 September 2017; Published: 18 October 2017

Keywords: peer advising, learning center, honors

\section{The Need}

The 1,500 students in the Virginia Tech Honors College are asked to be highly independent: within a set of parameters, they design their own honors education by selecting the opportunities that will best enrich their individual course of study. Students benefit from personal guidance during this complex planning process. Historically, our honors directors offered limited honors advising as needed. However, as we transition from honors program to college, our services are growing in scope and complexity, as are our responsibilities. We need a new way to provide reliable, personalized honors student support.

\section{Our Solution}

Learning centers have been shown to increase student retention, satisfaction, academic achievement, and self-reliance (Cuseo, 2003; Pascarella \& Terenzini, 1991; Smith, Walter, \& Hoey, 1992), all outcomes that we hope to foster as we grow. And while community connection and campus involvement are instrumental in helping all students thrive, it has shown to be particularly essential for honors students, who need a community of academic peers (Cuevas, 2015).

Fortunately, Honors at Virginia Tech already has a thriving culture of peer education: our peer educators are the primary instructors of our first-year seminars and reading seminars, classes that are taken by hundreds of students every semester and that consistently receive outstanding course evaluations.

Therefore, to increase student support in the context of our intellectual community, we decided to create a learning center grounded in our strength: an Honors Peer Advising Center.

\section{The Writing Center Model}

To structure this new initiative, we turned to the writing center model because of how well its goals complement our own. Writing centers are designed to engage students as active 
participants in their own problem-solving, leaving them better equipped with the skills and confidence to approach writing problems more effectively. According to Muriel Harris (1988) in "The Concept of a Writing Center," writing centers share the following characteristics:

1. One-on-one tutorials are the primary service.

2. Tutors are coaches and collaborators, not judges or evaluators.

3. Each student's individual needs are the focus of the tutorial.

4. Hands-on experimentation and practice are encouraged.

5. Centers are inclusive of students from any background, discipline, or level in school.

These approaches align nicely with the needs of an honors peer advising center:

1. Since honors students already seek out faculty and mentor interactions, they would likely value the focused attention of knowledgeable peer advisors.

2. Peer education already inherently involves collaboration, facilitation, and helpingnot judging.

3. Individualized support is a logical and effective way to address questions or issues that arise from individualized honors education.

4. Honors students might be more willing to practice or test unfamiliar ideas around a peer.

5. A generalized, non-disciplinary structure is essential for an honors college with firstthrough fifth-year students from all of the disciplinary colleges.

\section{The Honors Peer Advising Center}

This fall, we are opening the Honors Peer Advising Center (HPAC), in which trained honors peer advisors teach honors students the strategies and resources to solve honors-related problems. The Center's primary service will be one-on-one sessions, either 30 or 60 minutes each, that closely mirror the writing center philosophy. Any honors student can make up to 15 appointments each semester. We also plan to offer occasional small-group workshops on topics of common interest to honors students. These workshops will begin with a presentation and then let attendees work on their own related projects with the help and supervision of the peer advisors.

\section{Honors Peer Advising Needs}

To anticipate our students' peer advising needs, we asked our current and recent peer educators what kinds of honors-related questions their students asked. They responded that the most common questions related to:

1. Honors credit and diplomas

2. Role of honors staff members

3. Balancing honors and major requirements

The first and third categories align with what we expected: students have the challenging task of telling us how they will balance Honors with their other commitments, which requires high fluency in our academic policies. We anticipate that much of the peer advisors' work will involve helping students translate policies and opportunities into students' individual contexts. The second area of confusion surprised us since we have descriptive working titles: e.g., Director of Honors Admissions or Director of Major Scholarships. Nevertheless, this issue underscores the usefulness of a one-stop shop like the HPAC- 
students do not have to determine the best audience for their question before going in to ask it.

\section{The Honors Peer Advisors}

For the 2017-2018 academic year, we selected seven peer advisors. These students applied for the opportunity and were selected based on their desire and ability to help their peers, and their experience in areas such as mentoring, teaching, Honors, and Virginia Tech resources. The peer advisors will take a two-credit Honors Peer Advising Practicum each semester while they serve. Since we cannot pay them, this course enables us to offer academic and honors credit for the experience while also training, supervising, and teaching relevant educational techniques in the context of their day-to-day work. The course will involve reflection, role playing, skill observations, and semester projects to improve the HPAC in ways identified by the peer advisors.

\section{Anticipated Use}

Beginning in the fourth week of the semester, the peer advisors will each offer five hours of peer advising every week, or up to 70 half-hour appointments overall. While we cannot know for sure how many students will sign up, we are requiring over 200 incoming students to get their proposed honors plan of study approved through the HPAC. This requirement alone will generate one or more appointments per student, and we expect that others will seek voluntary assistance, as well.

\section{Looking Ahead}

Perhaps the most challenging part of this endeavor is acknowledging that we cannot know how to run the Honors Peer Advising Center until we are running it-and probably well after. We can use an established structure and prepare to answer previously asked questions, but this is ultimately still a new resource that will take time to refine and integrate into our College culture. The practicum should help by providing an opportunity for us to regularly discuss issues and our responses, but I expect our flexibility to be tested. We will probably struggle to obtain resources until we can demonstrate a need for them and prove our value.

\section{Acknowledgments}

I would like to thank Paul Heilker, Sara Vandyke, Paul Knox, and Jason Crafton for their support of this research. I would also like to acknowledge the George Mason University Writing Center, whose strong example inspired our approach.

\section{References}

Cuevas, A.E.P. (2015). Thriving in college: Predictors of honors student academic, psychological, and social well-being (Order No. 3715833). Available from ProQuest Dissertations \& Theses Global. (1708942472).

Cuseo, J.B. (2003). Comprehensive academic support for students during the first year of college. In G.L. Kramer et al. (Eds.), Student academic services: An integrated approach (pp. 271-310). San Francisco, CA: Jossey-Bass. 
Harris, M. (1988). Writing center concept. Retrieved from International Writing Centers Association. National Council of Teachers of English. http://writingcenters.org/writingcenter-concept-by-muriel-harris (August 8,2017 )

Pascarella, E.T. \& Terenzini, P. (1991). How college affects students: Findings and insights from twenty years of research. San Francisco, CA: Jossey-Bass.

Smith, J.B., Walter, T.L., \& Hoey, G. (1992). Support programs and student self-efficacy: Do first-year students know when they need help? Journal of the Freshman Year Experience, 4(2), 41-67. 